\title{
Discussion: following keynote address from Professor Christine Borgman
}

\section{Bob Campbell}

Online providers of information have reduced the burden on libraries to archive materials, and have thus saved them a significant cost. Are libraries now able to pay more to the publishers for the materials they access?

\section{Christine Borgman}

No. This new electronic situation has not reduced costs, and has in fact created new problems. There is a great need to create built-in archiving processes online. No publisher currently guarantees that the information is being archived or will be made permanently available online. One possible solution that has been suggested is that multiple repositories should be maintained around the world to ensure long-term availability and, related to this, there is also a need for economic models of purchase and renewal. At the University of California, they have created a Digital Library that is accessed from all nine independent campuses. Such aggregations could be used beneficially in publisher negotiations to forward the need for archiving.

\section{Fytton Rowland}

How can the citation analysis process be speeded up, as the current citation process experiences a time-lapse problem?

\section{Christine Borgman}

I think this is stretching the concept. There is a necessary time lag, which is shortened if publications are electronic. However, flows of reading can be studied instead of the citations to increase currency. We can trace what is being read, perhaps by using regular use models.

\section{Don King}

Studying reading flows are useful for increasing current awareness about what is being read in a particular field at a particular time, but the older materials are the most useful. Furthermore, research needs are not immediate, so time lapses in citation processes are inevitable.

\section{Christine Borgman}

I think richer models are required. Preprint exchanges, for example, can't be captured by citation analysis, and this flow of communication needs to be studied and monitored as well.

\section{Don King}

Whereas subjects such as high energy physics only experience a short time lag before research is read and cited, those in the fields of humanities require a longer period, as the research conducted in the latter does not need to be so current. 
Micheline Beaulieu

Cited materials are the most easily accessible. How can we find out about general communication flows, or research that has not yet been published?

\section{David Pullinger}

All research is done within communities and researchers have a desire to know what their colleagues are reading, in order to keep up in the field. Preprints don't exist in all fields, so it is hard to track such communication channels. Researchers in some fields are very secretive and don't disclose much information about their studies until the research is published.

\section{Christine Borgman}

Also, academic librarians have a sense of equity and try to treat all departments the same, when they are in fact highly different. Customisation is required in order to meet the varying needs of the different fields. Librarians have a tendency to ignore the information/ communication flows that users experience before they walk into the library.

David Russon

What will the impact be of knowing who is reading what within a field? Would it, for example, lead to "Top Ten" listings as is currently the case with book sales?

Christine Borgman

Agenda setting research should be undertaken in order to discover these potential outcomes. 